MAHMOUD ELMORSSY, Ph.D. Candidate ${ }^{1}$

E-mail: elmorssy@itu.edu.tr

HÜSEYIN ONUR TEZCAN ${ }^{1}$

(Corresponding author)

E-mail: tezcanhu@itu.edu.tr

${ }^{1}$ Istanbul Technical University, Faculty of Civil

Engineering, Department of Transportation

Maslak, Istanbul, Turkey
Science in Traffic and Transport Original Scientific Paper Submitted: 22 Mar. 2019 Accepted: 27 Nov. 2019

\title{
ORDERED GENERALIZED EXTREME VALUE MODEL AS A TOOL FOR DEMAND MODELLING OF DISCRETIONARY TRIPS
}

\begin{abstract}
Although the four-step model is the most common method in transportation demand modelling, it is exposed to a considerable criticism in terms of representing the actual choice behaviours of travellers. For example, the four steps are presented in a fixed sequence and independently from each other. Such assumption may be correct in case of obligatory trips (e.g. work trips) where travellers' behaviour has usually no effect on trip generation or trip distribution stages. However, in discretionary trips, they may simultaneously decide on various trip dimensions. This paper tries to overcome the limitations of traditional four-step model associated with discretionary trips by using a joint discrete choice modelling approach that represents destination, departure time and travel mode choices under a unified framework. The proposed model to be used is the Ordered Generalized Extreme Value model where potential spatial correlation among discretionary destinations can be considered as well. The research methodology has been tested by using shopping and entertainment trips data of Eskisehir city in Turkey. The proposed framework seemed to be more effective and offered an accurate alternative to the first three stages of the traditional four-step model in a setting with a limited number of discretionary destinations.
\end{abstract}

\section{KEY WORDS}

Ordered Generalized Extreme Value model; destination; departure time; discretionary trips; travel demand modelling; traditional four-step model; travel mode;

\section{INTRODUCTION}

Since the four-step model was developed in the 1960 s, the sequence of the steps has remained unchanged [1]. For instance, it is assumed arbitrarily that trip distribution (destination choice) comes in the second step and independently followed by travel mode choice. However, that sequence may be violated in discretionary trips (i.e. non-obligatory trips) where travellers may simultaneously decide on destination, travel mode and other considered travel dimensions such as departure time [2].

Considering the trip distribution stage over years, there is a serious competition between destination choice models on one side and other conventional methods (e.g. growth factor methods, gravity models, etc.) on the another [1]. Although destination choice models show better performance in terms of goodness-of-fit and predictability, the two competing approaches are similar in the distribution theory. That is, all of them ignore the potential interaction between destination choice and other travel dimensions that may exist within the same choice situation. For example, for discretionary trips and in case of a congested network, most destination distribution models assume compensations between closer destinations depending on the relative origin - destination impedance function (e.g.travel time). However, this assumption ignores the fact that individuals may shift their departure time or change the travel mode to travel to their desired destination. On the other hand, most studies that considered the interaction between destination choice and other simultaneous choices did ignore the potential spatial correlation between different destinations [3].

As there is a gap in the literature about representing a unified model that connects destination choice with other travel dimension choices, this research contributes to filling this gap through applying the Ordered Generalized Extreme Value (OGEV) model. Such a model will account for spatial correlation among different discretionary destinations along with considering simultaneous choices of two of the most significant travel dimensions which are departure time and travelling mode. The proposed 
approach can be seen as a more accurate and efficient alternative for the first three steps of the traditional four-step model in forecasting and planning issues especially when the scale is small or medium sized (e.g. small and medium sized cities).

\section{LITERATURE REVIEW}

The choice modelling approach is usually used only for modal split stage in most of the traditional four-step models with little or no deployment in other stages [3]. For instance, in most applications, aggregate gravity models are used extensively in trip distribution stage independently from travel mode choice stage. However, recently, the discrete choice models have been introduced as an alternative to conventional gravity models to represent destination choice along with other travel choices (e.g. departure time and travel mode choices) [4]. Such a representation has served different modelling approaches (e.g. trip-based and activity-based models) [5-9] either as a part of the four-step model or as independent models [10,11]. Through the following text, light is shed on some of the related studies that used choice modelling as an alternative to traditional four-step models for demand modelling.

With regard to using choice modelling for the destination choice (i.e. trip distribution), methodology and applications of models have been defined firstly in 1977 by Ben-Akiva [12]. However, Daly (1982) [13] analysed the attractiveness of destinations in such models. This approach was followed by studies that adopted different discrete choice models for different trip purposes. For example, Pozsgay and Bhat (2001) [10] developed a homebased entertainment destination choice model that considered a lot of trip attributes and socio-demographic characteristics of individuals as variables. They concluded that adjacent recreational zones are more likely preferred than the isolated ones. Similarly, in Switzerland, Simma et al. (2001) [14] proposed a leisure destination choice model that accounted for some destination attractiveness variables (e.g. number of swimming pools). As a result, the origin - destination distance was found to be the most important factor that affects the individuals' leisure destination choices. Mishra et al. (2013) [15] introduced a Multinomial Logit (MNL) destination choice model for Maryland. Through comparison with traditional gravity model, the destination choice model was found better for state-wide travel demand modelling. Another research that recently represented the individuals' behaviour while choosing among entertainment destinations is the one attained by Hassan et al. (2017) [16]. They studied the choice of destination according to the type of recreational activity (e.g. dine and drink, gym, park, etc.) in Victoria, Australia. The average behaviour of all activities was introduced through developing a combined fuzzy MNL model that consists of all activities together. The study concluded that the most important factors that affect the individuals' destination choices are travel time, number of origin - destination trips and level of urbanization. Additionally, the individuals' characteristics such as age, income and employment status have some significant effects on their destination choices.

Another important travel dimension that is considered in this analysis along with the destination choice is the departure time choice. The importance of modelling the departure time as a part of the trip decision arises from the need to better understand the inter-relationship between congestion and the distribution of trips over different times of day. In the context of time representation approaches, while some studies have developed discrete choice-based departure time models [17-19] others have adopted the continuous representation of time through different modelling techniques such as MNL, Nested Logit (NL), etc. [20-22]. Moreover, under the umbrella of activity-based modelling, some scholars have examined the effects of time of day choices on the daily activity patterns [20-23]. In addition, in some other studies the effects of departure time were examined from a tour-based modelling viewpoint $[24,25]$.

Considering the approaches that jointly represented destination choice with other travel dimension choices, Bowman and Ben-Akiva (2001) [26] introduced an integrated destination choice activity model system that can generate time and mode-specific trip matrices. By using a multi-level NL model, they assigned one branch for departure time choices and another branch for combinations of travel mode and destination choice. However, each level is estimated separately rather than simultaneously with other levels. Likewise, [25, 27, 28] developed unified destination-mode-choice models that represent the influence of mode choice on destination choices through imposing the log-sum parameter of mode choice as a parameter in the destination choice. 
It is worth mentioning that a common significant feature in most of the above pointed studies is that they do not consider the potential correlation among destinations. Instead, they treat them as mutually exclusive alternatives with identical independent distribution (IID) for their error terms. However, there are many sources of potential correlation between destination alternatives. For example, a spatial correlation between adjacent zones may exist due to the arbitrary definition of their boundaries [16]. Such a definition is usually unknown to most of the travellers which leads them to construct their own boundaries in their minds depending on the unknown factors.

An approach that can effectively connect the destination choice with the departure time and travel mode and consider various potential spatial correlations among the destinations is the OGEV model [29]. OGEV allows destinations that are located (ordered) in a specific pattern to have common unobserved errors. This paper argues that an efficient joint model for destination, departure time, and travel mode choices can be attained through using the OGEV model.

\section{PROPOSED FRAMEWORK}

Through OGEV, the spatial effect of discretionary destinations on both departure time and travel mode choice can be more accurately represented.
Indeed, it provides a more accurate representation for the ordered nature among neighbouring destinations. The OGEV model was proposed by Small in 1987 [29] under the context of departure time choice modelling. It is considered as a special case of Cross Nested Logit (CNL) model, in which alternatives within a specific nest may occur in other nests if there are other potential unobserved similarities. However, in OGEV, similarities between alternatives are controlled by the relative closeness among them. In order to effectively use OGEV to jointly model the discretionary destination, departure time and travel mode choices, a general framework that organizes the proposed modelling process is illustrated in Figure 1.

For specific discretionary trips, suppose an individual $i$ who chooses jointly to travel to a specific discretionary destination $d$, at specific departure time $t$ and by a specific travel mode $m$ from a choice set that has $D \times T \times M$ alternatives, where $D, T$ and $M$ are the total number of destinations, departure times and travel modes within the choice set, respectively. Equation 1 shows the proposed form of the deterministic component for the underlying utility function.

$$
V_{d, t, m}=A S C_{d, t, m}^{S}+\beta_{X}^{S} X_{d, t, m}+\beta_{Z}^{S} Z_{i}
$$

where:

$V_{d, t, m} \quad$-deterministic utility of individual $i$ for travelling to destination $d$ at departure time $t$ by using travel mode $m$;

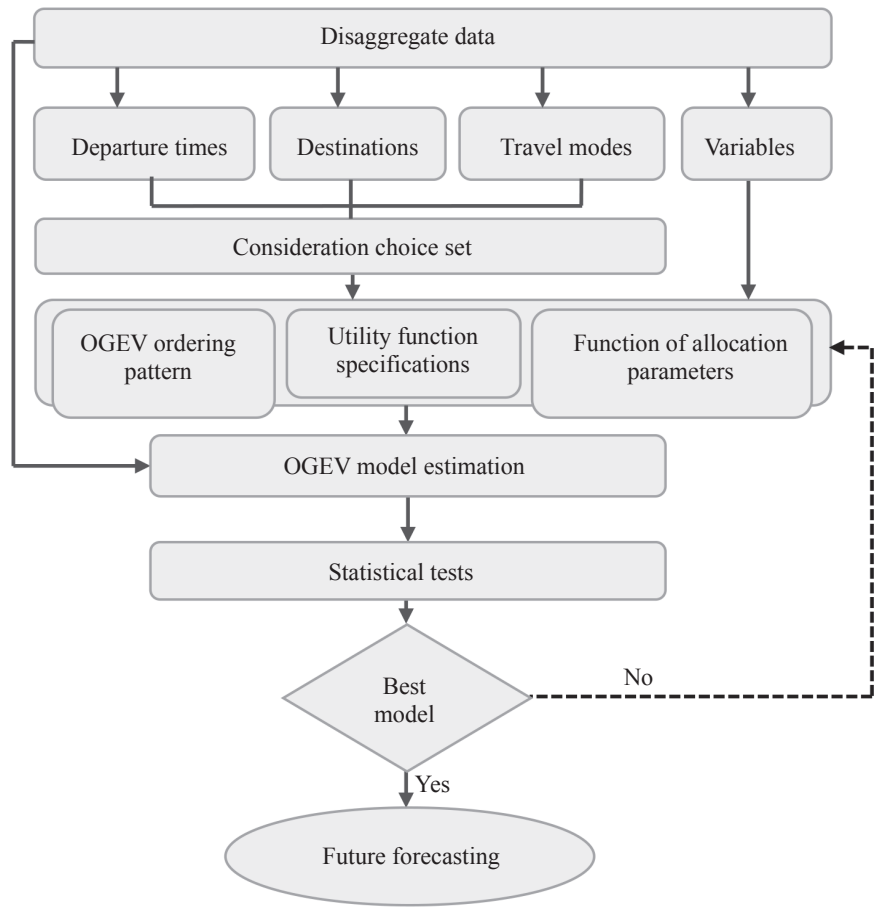

Figure 1-Proposed framework 
$A S C_{d, t, m}^{S}$-alternative specific constant specific to alternative(s) $S$;

$X_{d, t, m} \quad$-vector of attributes of alternatives;

$Z_{i}^{d, t, m} \quad$-vector of individual $i$ 's characteristics; $\beta_{X}^{S} \& \beta_{Z}^{S}$-coefficients of $X$ and $Z$ variables, specific to alternative(s) $S$.

The proposed two-level NL-OGEV model is structured as follows: destinations allocated to the upper level with the total number of branches equalling $D$. The lower level consists of all possible combinations of departure times $t$ and travel modes $m$ with equal $T \times M$ combinations. Additionally, the spatial correlation is represented by allowing some elementary alternatives to overlap the neighbouring destinations. Thus, the probability functions can be expressed as follows:

$$
\begin{aligned}
& P(d, t, m)=\sum_{k=d}^{k=D} P(d, t, m \mid k) P(k) \\
& P(d, t, m \mid k)=\frac{\left(\alpha_{d, t, m \mid k}\right) \frac{1}{\theta_{d, t, m \mid d}} \exp \left(\frac{V_{d, t, m}}{\theta_{d, t, m \mid d}}\right)}{\exp \left(I_{k}\right)} \\
& P(k)=\frac{\exp \left(\frac{\theta_{d, t, m \mid d}}{\theta_{O}} I_{k}\right)}{\sum_{k=d}^{k=D} \exp \left(\frac{\theta_{d, t, m \mid d}}{\theta_{O}} I_{k}\right)} \\
& I_{k}=\log \sum_{d, t, m \mid k}^{D, T, M \mid k}\left(\alpha_{d, t, m \mid k} \frac{1}{\theta_{d, t, m \mid k}} \exp \left(\frac{V_{d, t, m}}{\theta_{d, t, m \mid d}}\right)\right.
\end{aligned}
$$

where:

$\alpha_{d, t, m \mid k}$-the portion of existing alternative $d, t, m$ in nest $k$ (allocation parameter);

$\theta_{d, t, m \mid d}$-error terms scale parameter of $d, t, m$ conditional on $d$;

$\theta_{O} \quad$-overall scale parameter (usually normalized to 1.0);

$I_{k} \quad-$ Expected Maximum Utility of nest $k$ (inclusive value or log-sum value).

Moreover, a linear parameters function that involves the effect of a specific variable has been used to distribute the alternatives among different nests (i.e. allocation parameter) [8]. As shown in Equation 6, rather than the intercept, a variable that may affect the value of allocation parameters will be considered. Indeed, a lot of available variables may be categorized as attributes for destinations that influence the similarities between alternatives in different nests such as travel time, travel cost, and travel distance. Yet, in order to avoid adding complexities to the proposed model, only one of them was considered.

$W_{\alpha_{d, t, m \mid k}}=\gamma_{d, t, m}+\delta_{d, t, m} Y_{d, t, m}$ where:

$W_{\alpha d, t, m \mid k}$-deterministic utility of allocation parameter of alternative $d, t, m$ conditional on destination $k$;

$\gamma_{d, t, m}$-alternative constant specific to $d, t, m$ alternative;

$\delta_{d, t, m} \quad$-parameter of $Y$ variable specific to $d, t, m$ alternative;

$Y_{d, t, m}-$ a variable that affects the value of allocation parameter alternative $d, t, m$.

The occurrence of specific $d, t, m$ alternative in a number of $k$ 's nests depends on the proposed ordering pattern. For instance, if geographical location ordering is considered, thus, $d, t, m$ alternative that is related to a destination $d$ will occur in other adjacent alternatives which may be placed before or after $d$. That is, according to the considered order of destinations, adjacent destinations will host common alternatives. However, the decision about the considered order of destinations is disputable. Notably, most of the previous studies adopted geographical location-based (Geo-based) ordering which mainly relies on distances between destinations [16]. In this research, along with Geo-based ordering, an average travel time between origins and destinations (ATT OD-based) ordering is considered. Thus, this research establishes an important definition for the term closeness. It is argued that the average travel times from origins to destinations offer a much better explanation which may lead to more plausible representation. The reason is that the in-between distances are not essential representing the actual approximation among destinations (they may do with high degree of certainty for private car trips) since in some cases closer destinations have much higher travel time, especially for public transportation $p t$ trips. This case may occur frequently in urban transportation systems that contain various $p t$ facilities with a number of transfer centres and various access points. Thus, in terms of $p t$ trips, two geographically adjacent destinations may have extremely different travel times due to different $p t$ accessibilities.

Another important advantage of using ATT ODbased ordering is that it enables distribution of elementary alternatives from the main destination to other destinations individually. That is, the investigation of ATT OD values across departure times and travel modes may result in some alternatives of one destination to have similar average travel time with others from another destination. For example, for 
a choice situation, only private car trips at morning peak departure times may be common for various destinations; however, the same may not occur for other modes at different departure times. That makes the proposed approach more suitable for our choice situation since high degree of heterogeneity exists among alternatives within the same nest. In other words, the proposed approach makes it possible for us to assume various ordering patterns based on specific departure times and/or travel modes according to the value of ATT across them. Therefore, in order to demonstrate our idea, two different sets of nesting structures are proposed to be constructed and tested: geographic location-based ordered set and average travel time OD-based ordered set.

Another significant approach that is adopted in this research is the applied specifications associated with explanatory variables of the deterministic utility. That is, for all proposed OGEV structures, different specifications for model variables have to be proposed and tested in order to capture the best specification for each structure in terms of the magnitude of IV parameters, signs and the degree of significance of parameters as well as the overall goodness-of-fit of the model. For each proposed structure, different combinations of generic and alternative specific variables have to be assumed. Notably, representing parameters that are specific to all of the elementary alternatives will lead to a great number of estimates (i.e. DTM-1). Introducing this large number of estimates will not only add more encumbrances in the estimation process but it will also complicate the interpretation of the results. Therefore, in an attempt to intuitively interpret the results of the estimation as well as ease the estimation process, the alternative specific variables (especially those related to individual characteristics) are proposed to be specific to one or more travel dimensions rather than all the elementary alternatives. For instance, in some specifications, the parameter of age variable may be specific to departure time alternatives; however, in other specifications, it may be assumed specific to destination or travel mode alternatives.

\section{CASE STUDY}

In this paper, the proposed framework is tested by using the shopping and entertainment trip data of Eskisehir city, Turkey. These data have been collected through a household survey that was conducted in 2015 in the context of Eskisehir Master Plan study which was operated by the Eskisehir Metropolitan Municipality. Eskisehir city (Eskişehir in Turkish) is a city in north-western Turkey and the capital of the Eskişehir Province. It is considered as a medium sized city with a population of 799,724 (2013 census) distributed over about $2,678 \mathrm{~km}^{2}$ area.

The considered shopping and entertainment trips data are a part of large-scale revealed preference data which include household and individual socio-demographics, individual's travel information, attributes of used transportation mode(s). In the city, the most attractive shopping and entertainment activities are concentrated in three distinct regions (Figure 2) which are distinguished by providing a lot of retail and entertainment activities. These regions can be named

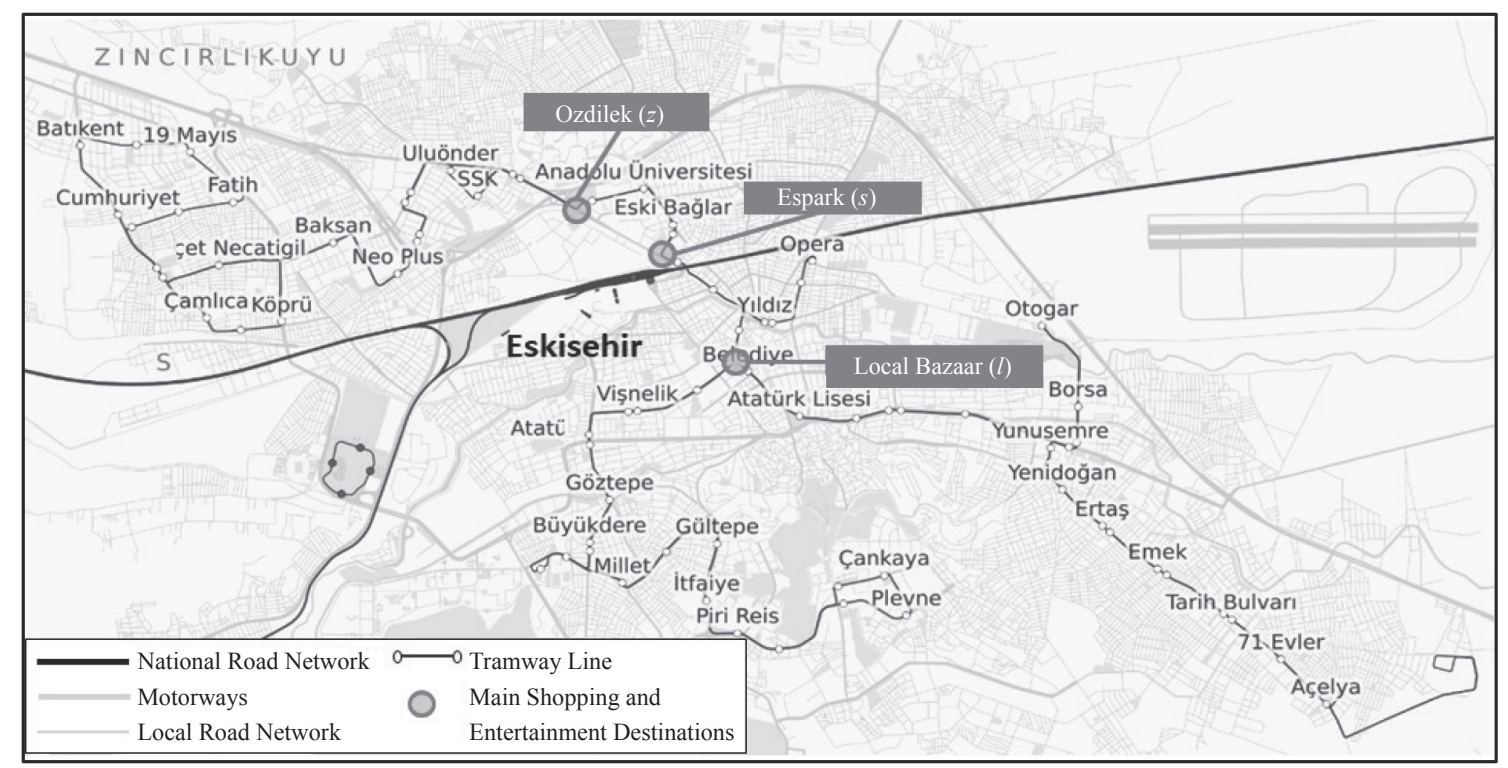

Figure 2 - Eskisehir city map 
as ESPARK shopping centre (s), Ozdilek shopping centre $(z)$ and Local Bazaar $(l)$. Regarding departure time, it has been categorized into three different groups that differ in traffic conditions and availability of individual's free times (Table 1). In the context of travel mode, three modes that access the three destinations and are available during the three departure times have been considered in our analysis and these are: private car $(c)$, public bus $(b)$ and tramway $(t r)$.

There were a total of 529 observations. The distribution of individuals among available alternatives of each choice subset is shown in Table 2. Moreover,

Table 1 - Categories of departure times

\begin{tabular}{||c|c||}
\hline Departure time periods & Time intervals \\
\hline \hline Peak $(p)$ & $7.00-9.00$ and $16.30-18.30$ \\
\hline Off-peak $(o)$ & $9.00-16.30$ \\
\hline Evening $(e)$ & $18.30-22.00^{*}$ \\
\hline
\end{tabular}

*observations after 22.00 have been neglected since they are trivial and happen after mandatory closing hours the average travel time form origins to the considered destinations for private car and public transit users are shown in Table 3. Finally, Table 4 illustrates the explanatory variables that are considered in the estimated utility functions. Other variables related to the attributes of destinations such as the number of shopping and entertainment activities might have significant effects; however, unfortunately, they were unavailable within the collected data.

\section{OGEV-STRUCTURES}

In order to model the individuals' shopping and entertainment destination, departure time and travel mode choices in Eskisehir city, a number of OGEV structures has been proposed and tested. Each proposed structure consists of two levels with 27 elementary alternatives. The upper level has three branches, one branch for each destination. Under each branch, a set of nine elementary alternatives (three departure times $\times$ three modes) which are

Table 2 - Distribution of sample among alternatives

\begin{tabular}{||l|l|c|c||}
\hline & & \# of Observations & Share \% \\
\hline \hline \multirow{5}{*}{ Departure time $(t)$} & Peak $(p)$ & 104 & 19.66 \\
\cline { 2 - 4 } & Off-peak $(o)$ & 277 & 52.36 \\
\cline { 2 - 4 } & Evening $(e)$ & 148 & 27.98 \\
\hline \multirow{5}{*}{ Destination $(d)$} & Espark $(s)$ & 184 & 34.78 \\
\cline { 2 - 4 } & Local Bazaar $(l)$ & 203 & 26.37 \\
\cline { 2 - 4 } & Ozdilek $(z)$ & 142 & 21.93 \\
\hline \multirow{3}{*}{ Transportation modes $(m)$} & Car $(c)$ & 116 & 18.53 \\
\cline { 2 - 4 } & Bus $(b)$ & 98 & 59.55 \\
\cline { 2 - 4 } & Tramway $(t r)$ & 315 & \\
\hline
\end{tabular}

Table 3 -Average Travel Time from origins to considered destinations (ATT OD - Minutes)

\begin{tabular}{||l|c|c|c|c|c|c|c|c||}
\hline \multirow{2}{*}{ Destination } & \multicolumn{4}{|c|}{ Car $(c)$} & \multicolumn{4}{c||}{ Public transportation $(p t)$} \\
\cline { 2 - 18 } & Peak $(p)$ & Off-peak $(o)$ & Evening $(e)$ & Average & Peak $(p)$ & Off-peak $(o)$ & Evening $(e)$ & Average \\
\hline \hline Espark $(s)$ & 33 & 32.9 & 28.3 & 31.4 & 37.9 & 31.7 & 33.2 & 34.3 \\
\hline Ozdilek $(z)$ & 32.9 & 33 & 28.7 & 31.5 & 36 & 34.5 & 35.3 & 35.3 \\
\hline Local Bazaar $(l)$ & 32 & 31 & 33.5 & 32.2 & 36 & 34.8 & 36 & 35.6 \\
\hline
\end{tabular}

Table 4-Model variables

\begin{tabular}{||c|c|l|l||}
\hline \multicolumn{1}{|c|}{ Type of variable } & Abbreviation & \multicolumn{1}{|c||}{ Description } & \multicolumn{1}{|c||}{ Unit } \\
\cline { 2 - 4 } Alternative's attribute & TT & Total travel time & Minutes \\
\cline { 2 - 4 } & TC & Total travel cost & Turkish Lira \\
\hline \multirow{3}{*}{ Traveller's characteristics } & COW & Car ownership & Dummy $(0.1)$ \\
\cline { 2 - 4 } & INC & Household monthly income & Turkish Lira \\
\cline { 2 - 4 } & SS & Student status & Dummy $(0.1)$ \\
\cline { 2 - 4 } & AGE & Age of individual & Years \\
\hline
\end{tabular}


related to the considered destination are allocated. Moreover, according to the proposed spatial correlation pattern (destinations order), some elementary alternatives are common between multiple destinations. Figure 3 represents an example of one of the proposed OGEV structures.

As pointed out previously, the order of destinations can be geographically location-based, ATT OD-based or a hybrid of both according to travel mode. This paper argues that hybrid sorting may lead to more representative OGEV structures, especially for cases in which closer destinations have considerable different average travel times from the origins. This situation can be clearly observed in this case study where, although there is a remarkable closeness between Espark and Ozdilek rather than between Ozdilek and Local Bazaar (Figure 2), the average travel time between OD of $p t$ trips (Table 3) suggests another assembling. Practically, according to Figure 2, it may be convenient to assume similarities between Espark and Ozdilek. This aggregation is true for private car trips only since the average travel times of private car trips are almost the same for the three destinations over different departure times (Table 3). However, the average travel times of $p t$ trips (bus and tramway) indicate that a trip between Ozdilek and Local Bazaar may have much more common errors than a trip between Espark and Ozdilek through all times of the day. An OGEV model can represent such hybrid similarities through assigning private car-departure time alternatives to be common within Espark and Ozdilek nests and assigning public transportation-departure time alternatives to be common in Local Bazaar and Ozdilek nests.

Moreover, in order to express the dominance of the proposed ordering approach over other ordering patterns, some "Geo-based only" and "ATT ODbased only" structures are estimated as well. Overall, four different OGEV structures are constructed and estimated (Table 5).

As illustrated in Table 5, the NS_Hybrid exhibits hybrid ordering patterns whereas public transit-based alternatives pt-based are common in both Ozdilek and Local Bazaar nests (average travel time-based ordering) and private car-based c-based alternatives are common in Espark and Ozdilek alternatives (geographical location-based ordering). In NS_ATT, only the potential similarities between Ozdilek and Local Bazaar for public transportation-based alternatives are considered (only average travel time-based ordering). This structure ignores any similarities coming from adjacent locations and accounts only for the nearer average travel times. Therefore, it ignores the similarities of private carbased alternatives between Espark and Ozdilek. Besides, NS_Geo1 and NS_Geo2 completely ignore the average travel time-based assembling and consider only the geographical location for aggregating alternatives. In other words, in NS_Geo1, regardless of type of the transportation mode, similarities of Espark with Ozdilek on one side and Ozdilek with Local Bazaar on the other side are assumed. In NS_Geo2, however, a sole overlap between Espark and Ozdilek is proposed.

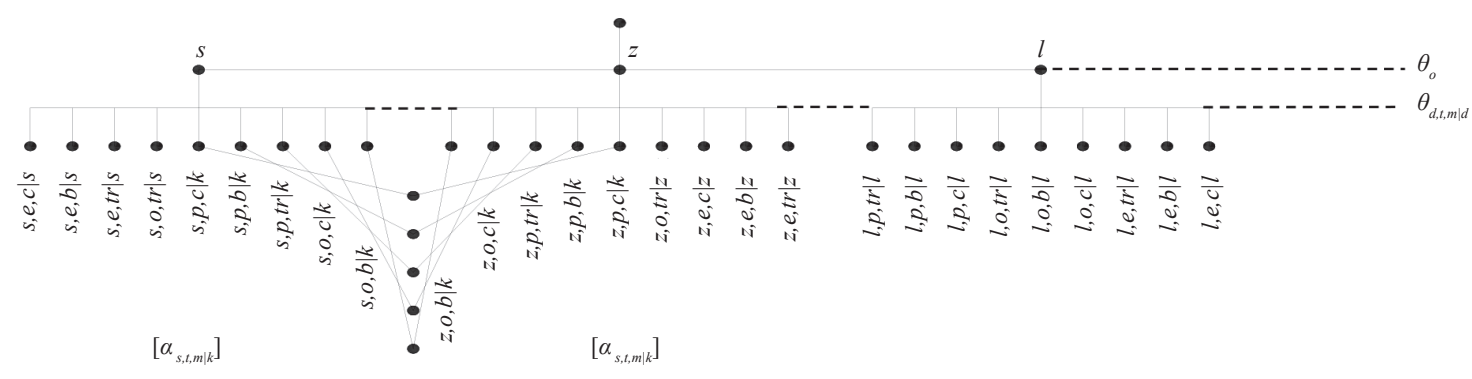

Figure 3 - Example for a geographical location-based OGEV structure

Table 5 - Proposed ordered nesting structure

\begin{tabular}{||l|c|l||}
\hline \multicolumn{1}{|c|}{ Ordering pattern } & Abbreviation & \multicolumn{1}{|c|}{ Description } \\
\hline \hline Hybrid & NS_Hybrid & $\begin{array}{l}\text { pt-based alternatives } \in z \text { and } l \& \\
\text { c-based alternatives } \in z \text { and } s\end{array}$ \\
\hline ATT OD only & NS_ATT & pt-based alternatives $\in z$ and $l$ \\
\hline Geo-based only & NS_Geo1 & $\forall d, t, m \in z$ and $s \& \forall d, t, m \in z$ and $l$ \\
\hline Geo-based only & NS_Geo2 & $\forall d, t, m \in z$ and $s$ \\
\hline
\end{tabular}




\section{ESTIMATION RESULTS}

The proposed OGEV structures were calibrated and estimated using the statistical package NLOGIT6. Regarding the scale parameter (dissimilarity), the overall scale parameter at the top level is assumed to be equal to one (normalization). This specification requires lower level scale parameters to be less than or equal to one to assure a lesser variance of error terms for elementary alternatives and more than zero to ensure a convex log likelihood function.

Linear in parameter utility functions have been formulated and different determined specifications for their variables have been assumed and tested until reaching the best models in terms of goodnessof-fit, signs, magnitudes and statistical significance of the estimates. The following equation represents the best utility function and its associated variable specifications that contribute with the best statistical arguments of the proposed OGEV structures.

$$
\begin{aligned}
V_{d, t, m}= & A S C^{m}+b_{T T}^{t} T T+b_{T C} T C+b_{C O W}^{m} C O W+ \\
& b_{I N C}^{d} I N C+b_{S S}^{m} S S+b_{A G E}^{t} A G E
\end{aligned}
$$

where:

$A S C^{m}$-travel mode alternatives specific constant;

$b_{T T}^{t} \quad$-estimate of travel time parameter specific to departure time alternatives;

$b_{T C} \quad$-generic estimate of travel cost parameter;

$b_{C O W}^{m}$-estimate of car ownership parameter specific to travel mode alternatives;

$b_{I N C}^{d} \quad$-estimate of income parameter specific to destination alternatives;

$b_{S S}^{m} \quad$-estimate of student status parameter specific to travel mode alternatives;

$b_{A G E}^{t} \quad$-estimate of age parameter specific to departure time alternatives.

In addition to this setting, different variables have been imposed individually in the utility function of the allocation parameter. However, the average trip distance (ATD) has been found to increase the overall goodness-of-fit and other statistical arguments with more intuitive values for the allocation parameters (Equation 8).

$W_{\alpha_{d, t, m \mid d^{*}}}=\gamma_{d, t, m}+\delta_{d, t, m} A T D_{d}$

where $A T D_{d}$ is the average travel distance from origins to destination $d$

Table 6 expresses the estimation results of the four accepted OGEV structures. However, Table 7 shows the coefficient estimates of the allocation parameters for each structure. The following points summarize the most substantial analyses and conclusions that are extracted from Table 6:

- In terms of overall goodness-of-fit, all models achieve acceptable Log Likelihood (LL) ratio for convergence versus constant-only model. Yet, the highest value is associated with the NS Hybrid (212.4). This result is supported by the value of rho-squared as well (0.12). Additionally, compared with (MNL), the four ordering patterns seem to be significantly better. Further, compared with 3-level NL, all ordering structures show better LL except NS_ATT where a smaller LL has been reached.

- The values of the scale parameters are between zero and one for all models. Furthermore, their estimates are significantly different than zero.

- The parameters of the total travel time (specific to departure time) are found to be significantly different than zero at $90 \%$ level of significance with the expected negative sign in all models. However, NS ATT and NS Geol result in less convenient magnitudes since the influence of peak period travel times is slightly higher than off-peak period travel times. Indeed, most of the mode choice modelling literature supports that individuals may put much more emphasis on travel time in peak periods rather than off-peak, due to the extreme increase in congestion rates [30].

- As a generic parameter, total travel cost rationally occurs in negative sign with magnitudes that are statistically significant at $90 \%$-level of significance for all of the four structures. Yet, in all models except NS_ATT, relative to the parameter of total travel time, the individuals in Eskisehir city may give more importance to cost rather than time, while performing shopping and entertainment trips.

- The relative effect of travel time and traffic cost can be easily conveyed in a more accurate manner through calculating the value of time (VOT). By reviewing their values, VOT estimates associated with NS_ATT are found to be too high (10.30 and $8.45 \mathrm{USD} / \mathrm{hr}$ for peak trips, respectively). Still, NS_Hybrid and NS_Geol result in more plausible values (2.50 and 3.625 USD/ hr for peak trips, respectively). Obviously, for shopping and entertainment trips in Eskisehir city, the travellers have more willingness to pay for saving their trip time in peak periods than 
Elmorssy M, Tezcan HO. Ordered Generalized Extreme Value Model as a Tool for Demand Modelling of Discretionary Trips

Table 6 - Coefficient estimates for the proposed OGEV structures

\begin{tabular}{|c|c|c|c|c|}
\hline & NS_Hybrid & NS_ATT & NS_Geo1 & NS_Geo2 \\
\hline \multicolumn{5}{|l|}{ Constants } \\
\hline Car specific alternatives & $-3.87(-5.43)^{\mathrm{a}}$ & $-2.86(-5.82)^{\mathrm{a}}$ & $-3.26(-6.51)^{\mathrm{a}}$ & $-1.93(-5.75)^{\mathrm{a}}$ \\
\hline Bus specific alternatives & $-1.19(-4.63)^{\mathrm{a}}$ & $-0.9(-4.96)^{\mathrm{a}}$ & $-1.27(-8.05)^{\mathrm{a}}$ & $-0.60(-6.34)^{\mathrm{a}}$ \\
\hline Tram specific alternatives & $0.00(\mathrm{~F})$ & $0.00(\mathrm{~F})$ & $0.00(\mathrm{~F})$ & $0.00(\mathrm{~F})$ \\
\hline \multicolumn{5}{|l|}{ Total travel time } \\
\hline Peak specific alternatives & $-0.02(-3.34)^{\mathrm{a}}$ & $-0.011(-3.64)^{\mathrm{a}}$ & $-0.015(-3.90)^{\mathrm{a}}$ & $-0.01(-2.82)^{\mathrm{a}}$ \\
\hline Off-peak specific alternatives & $-0.01(-2.16)^{\mathrm{a}}$ & $-0.009(-3.05)^{\mathrm{a}}$ & $-0.012(-3.10)^{\mathrm{a}}$ & $-0.004(-1.6)^{b}$ \\
\hline Evening specific alternatives & $0.00(\mathrm{~F})$ & $0.00(\mathrm{~F})$ & $0.00(\mathrm{~F})$ & $0.00(\mathrm{~F})$ \\
\hline Total travel cost (Generic-TL) & $-0.24(-5.17)^{\mathrm{a}}$ & $-0.032(-1.75)^{b}$ & $-0.124(-3.74)^{\mathrm{a}}$ & $-0.17(-7.72)^{\mathrm{a}}$ \\
\hline \multicolumn{5}{|l|}{ Car ownership $(F=0 \& T=1)$} \\
\hline Car specific alternatives & $3.38(4.64)^{\mathrm{a}}$ & $2.56(5.1)^{\mathrm{a}}$ & $3.00(6.17)^{\mathrm{a}}$ & $1.57(4.85)^{\mathrm{a}}$ \\
\hline Bus specific alternatives & $0.00(\mathrm{~F})$ & $0.00(\mathrm{~F})$ & $0.00(\mathrm{~F})$ & $0.00(\mathrm{~F})$ \\
\hline Tram specific alternatives & $0.00(\mathrm{~F})$ & $0.00(\mathrm{~F})$ & $0.00(\mathrm{~F})$ & $0.00(\mathrm{~F})$ \\
\hline \multicolumn{5}{|l|}{ Age (years) } \\
\hline Peak specific alternatives & $0.00(\mathrm{~F})$ & $0.00(\mathrm{~F})$ & $0.00(\mathrm{~F})$ & $0.00(\mathrm{~F})$ \\
\hline Off-peak specific alternatives & $0.01(3.47)^{\mathrm{a}}$ & $0.02(4.93)^{\mathrm{a}}$ & $0.021(4.96)^{\mathrm{a}}$ & $0.01(4.67)^{\mathrm{a}}$ \\
\hline Evening specific alternatives & $0.00(\mathrm{~F})$ & $0.00(\mathrm{~F})$ & $0.00(\mathrm{~F})$ & $0.00(\mathrm{~F})$ \\
\hline \multicolumn{5}{|l|}{ Income (1,000 TL/Month) } \\
\hline Espark specific alternatives & NA & NA & $0.00(\mathrm{~F})$ & NA \\
\hline Ozdilek specific alternatives & NA & NA & $0.00(\mathrm{~F})$ & NA \\
\hline Local Bazaar specific alt. & NA & NA & $-0.081(1.72)^{b}$ & NA \\
\hline \multicolumn{5}{|l|}{ Student status (0\&1) } \\
\hline Car specific alternatives & NA & NA & $-1.24(-3.08)^{\mathrm{a}}$ & NA \\
\hline Bus specific alternatives & NA & NA & $0.00(\mathrm{~F})$ & NA \\
\hline Tram specific alternatives & NA & NA & $0.00(\mathrm{~F})$ & NA \\
\hline \multicolumn{5}{|l|}{ Value of time (US Dollar/h) } \\
\hline Peak specific alternatives & 2.50 & 10.30 & 3.625 & 1.75 \\
\hline Off-peak specific alternatives & 1.250 & 8.45 & 2.90 & 0.705 \\
\hline Evening specific alternatives & 0.00 & 0.00 & 0.00 & 0.00 \\
\hline \multicolumn{5}{|l|}{ Scale parameters (IVP) } \\
\hline$\theta_{s, t, m \mid s}$ & $0.73(5.27)^{\mathrm{a}}$ & $0.70(3.39)^{\mathrm{a}}$ & $0.76(10.64)^{\mathrm{a}}$ & $0.88(5.15)^{\mathrm{a}}$ \\
\hline$\theta_{z, t, m \mid z}$ & $0.25(\mathrm{~F})$ & $0.333(\mathrm{~F})$ & $0.57(1.66)^{\mathrm{b}}$ & $0.25(\mathrm{~F})$ \\
\hline$\theta_{l, t, m \mid l}$ & $1.00(8.24)^{\mathrm{a}}$ & $0.65(6.01)^{\mathrm{a}}$ & $1.00(\mathrm{~F})$ & $0.71(2.74)^{\mathrm{a}}$ \\
\hline \multicolumn{5}{|l|}{ Goodness-of-Fit } \\
\hline \# of observations & 529 & 529 & 529 & 529 \\
\hline \# of parameters & 41 & 33 & 43 & 40 \\
\hline $\mathrm{LL}(\beta)$ & $-1,517.20$ & $-1,541.00$ & $-1,531.65$ & $-1,524.18$ \\
\hline $\operatorname{LL}(0)$ & $-1,743.50$ & $-1,743.50$ & $-1,743.50$ & $-1,743.50$ \\
\hline $\mathrm{LL}(\mathrm{C})$ & $-1,623.40$ & $-1,634.33$ & $-1,610.74$ & $-1,618.80$ \\
\hline LL(3-level) & $-1,535.17$ & $-1,535.17$ & $-1,535.17$ & $-1,535.17$ \\
\hline LL(MNL) & $-1,550.24$ & $-1,550.24$ & $-1,540.02$ & $-1,550.24$ \\
\hline$-2 \operatorname{LL}(\beta$ vs. C $)$ & 212.4 & 186.66 & 158.18 & 189.24 \\
\hline Adjusted $\rho^{2}$ & 0.12 & 0.1 & 0.11 & 0.1 \\
\hline -2LL(OGEV vs. 3-level) & 35.94 & -11.66 & 7.04 & 22.00 \\
\hline
\end{tabular}

F=Fixed parameter, $N A=$ Not Applicable, ${ }^{a}$ Significant at $95 \%$ level, ${ }^{b}$ Significant at $90 \%$ level, $t$-statistics in parentheses 
Table 7 - Coefficient estimates of allocation parameters for the proposed OGEV structures

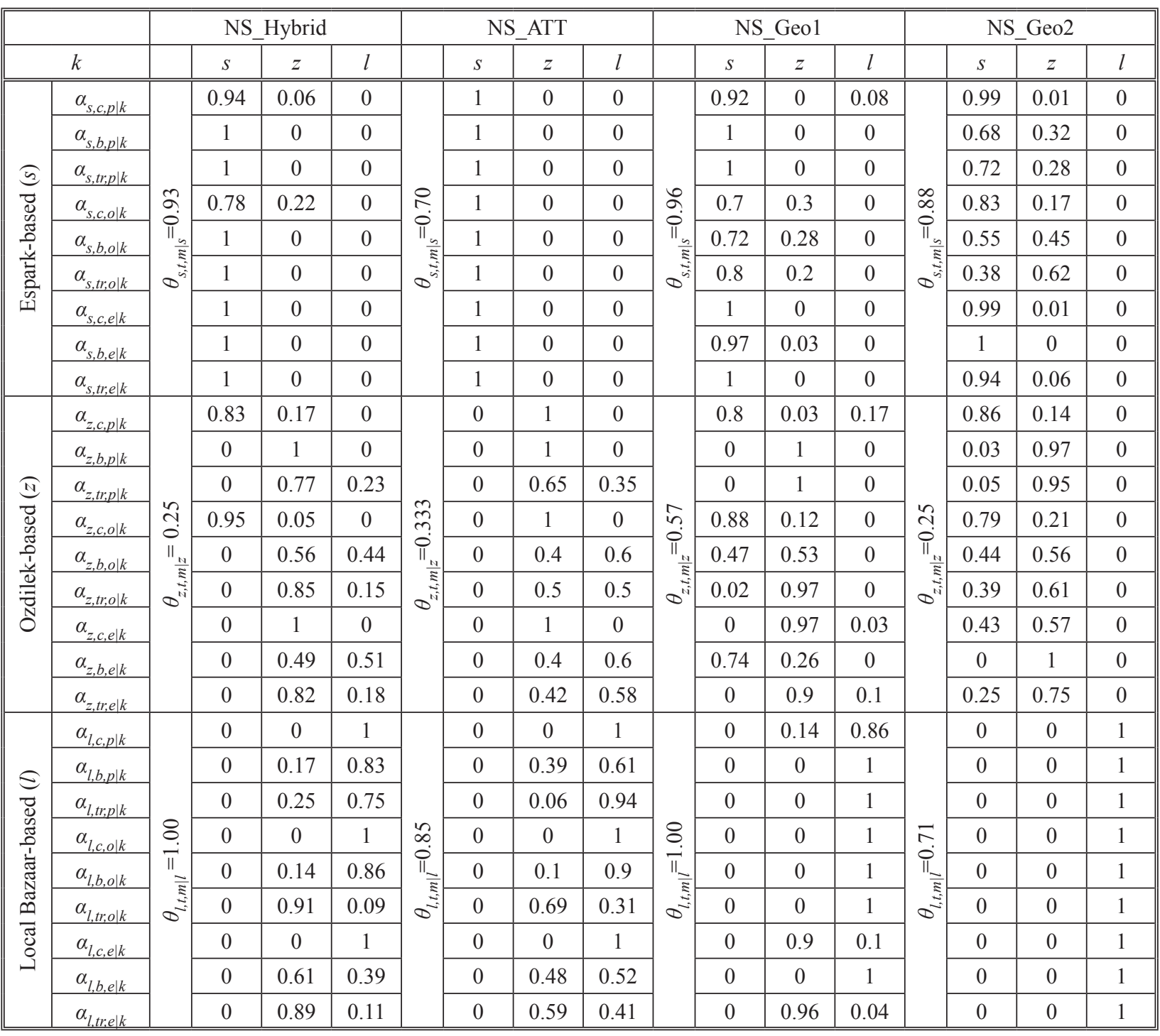

in off-peak and evening periods. Notably, the zero-value associated with the evening period comes from fixing the evening alternatives-specific travel time at zero (i.e. base alternatives).

- The value of car ownership estimates (specific to travel mode) show an inclination towards performing shopping and entertainment trips by using private cars rather than public transportation if the individual owns car(s).

- The off-peak alternatives-specific age coefficients are found to be significantly higher than zero for all OGEV structures. Obviously, the elderlies like to perform shopping and entertainment trips in off-peak periods rather than other times of the day.

- For monthly income variable, all applied specifications have not resulted in accepted estimates in all structures except NS_Geo1. The Local
Bazaar destination-specific parameter of monthly income is significantly less than zero. This parameter leads to a reasonable interpretation where the negative sign implies that high-income individuals are more likely to make their shopping and entertainment trips in shopping centres rather than local bazaars.

- Like monthly income, student status variable results in significant estimates for NS_Geol only. A significant and negative car alternatives-specific coefficient implies that, as expected, the students are more likely to use public transportation over private cars when heading to shopping and entertainment destinations.

Another significant output that may lead to crucial conclusions is the value of allocation parameters (Table 7). Obviously, the values of allocation parameter $\left(\alpha_{t, d, m \mid k}\right)$ can be clearly interpreted through 
analysing it along with scale parameters $\left(\theta_{d, t, m \mid d}\right)$. This can lead to the following important conclusions:

- For all OGEV structures, comparing with Ozdilek, the values of scale parameters associated with Espark and Local Bazaar destinations are closer to one. This suggests lesser correlation among alternatives allocated in Espark or Local Bazaar nests. However, the alternatives in Ozdilek nest may have higher correlation.

- On the other hand, the magnitudes of allocation parameters indicate that some alternatives have more probability to be in a more or less correlated nest rather than in their mother nest. For instance, the alternative of "travelling to Ozdilek at peak hour by using a car" is more likely to be with Espark nest, rather than Ozdilek $\left(\alpha_{z, c, p \mid s}=0.83\right)$. This may imply that this alternative may have less correlation with other Ozdilek alternatives $\left(\alpha_{z, c, p \mid z}=0.17\right)$.

- In NS_Hybrid, the relative values of $\alpha_{d, t, m \mid k}$ reveal some potential dependencies between Ozdilekbased and Local Bazaar-based alternatives. For example, travelling by tramway at peak period to Ozdilek has $23 \%$ probability to be similar with traveling by the same mode at the same time, but to Local Bazaar as a neighbouring destination.

- In NS_ATT, strong interaction between alternatives of Ozdilek and Local Bazaar destinations is expected because values of $\alpha_{d, t, m \mid k}$ are relatively close. For instance, high correlation may exist between Ozdilek and Local Bazaar for "departing at evening times by using a bus" since values of $\alpha_{d, t, m \mid k}$ suggest considerable interaction (e.g. $\alpha_{z, t r e \mid z}=0.42$ and $\left.\alpha_{z, t r, e \mid l}=0.58\right)$.

- For NS_Geo1, only three elementary alternatives have common effects between Espark and Ozdilek: car off-peak, bus off-peak and tramway off-peak. Contrary to previous structures, very low similarities are observed between Ozdilek and Local Bazaar nests. Notably, unlike travel time-based ordering, considering the geographical ordering of destinations does not lead to a proper representation.

- Finally, NS_Geo2 exhibits similarities produced from geographical order of Espark and Ozdilek only. The values of $\alpha_{d, t, m \mid k}$ suggest more substantial mutual effects of alternatives among both nests. Notably, connecting only Espark with Ozdilek has some uncertainties of expressing spatial correlation in a clear way. The reason is that being a shopping mall rather than local retails is another important attribute of Espark and Ozdilek which may lead to significant common error terms between them.

Overall, the signs and magnitudes of the utility function coefficients, value of time, overall goodness-of-fit and associated allocation parameters, lead to accepting the NS_Hybrid model as the best destination spatial correlation representative model. This supports the proposed approach of adopting the average travel time between origins and considered destinations ordering rather than geographical location ordering only.

\section{CONCLUSION}

This paper proposes the using of the discrete OGEV approach to represent discretionary destinations along with departure times and travel mode choices under a unified framework. It argues that individuals when deciding on discretionary trips are more likely to choose these three dimensions in a joint fashion rather than independently as assumed by the traditional four-step model. Moreover, the OGEV model can provide a better and simpler representation of the potential spatial correlation within various destinations. Further, the paper embraces a hybrid ordering pattern in which different bases for the order of destinations can be adopted. That is, along with the conventional geographical location-based ordering, an average origin-destination travel time-based ordering can be considered as well. This can represent readily the heterogeneity in individuals' perceptions toward urban discretionary destinations while evaluating different departure times and travel modes. In other words, the proposed approach allows the spatial correlation between destinations to differ from time to time and travel mode to another rather than assuming identical correlation pattern across them.

The proposed approach has been examined by using shopping and entertainment trips data of Eskisehir city, Turkey. Practically, four different OGEV structures that represent different ordering patterns among the main shopping destinations in the city have been constructed and the associated models have been estimated. In the light of estimation results, the following crucial conclusions have been reached:

- While performing shopping and entertainment trips, the individuals decide jointly on "to which destination", "at which time" and "by which 
mode", rather than independently. This could be discovered by examining the existence of statistical correlations among those three travel dimensions. This assumption has been proven in this case study where all the proposed OGEV structures have been statistically significant. Neglecting such dependencies (as adopting in traditional four-step model) means misrepresentation of actual travellers' behaviour for this type of trips which certainly lead to significant forecasting errors and distorted policy implications.

- Moreover, around all the proposed OGEV structures, hybrid-ordering pattern has shown the best performance in terms of overall goodness-of-fit, signs of estimates, values of scale parameters and value of allocation parameters. These can usefully help planners to clearly understand the individuals' behaviour which leads finally to proper policies and plans. For instance, the superiority of hybrid ordering pattern implies that individuals, while deciding on performing shopping and entertainment trips, are more likely to decide on the destination first, with correlation between destinations that have similar travel times. Consequently, they capture the proper departure time travel mode. Therefore, in order to mitigate congestion that is produced from this type of trips, transportation planners could suggest spatial-based measures rather than temporal-based ones.

- On the other hand, the proposed hybrid ordering pattern provides detailed analyses about the inter-relationships associated with various discretionary destinations, departure times, and travel modes where traditional four-step model cannot. This leads to more certain, specific, efficient, and precise policy decisions. For example, in Eskisehir city, while performing shopping and entertainment trips, public transportation users perceive common unobserved utility for Ozdilek and Local Bazaar destinations. On the other hand, private car users perceive similarities for Espark and Ozdilek. Thus, the policies that encourage the usage of public transportation will lead to entirely different results than policies that restrict the usage of private cars.

- Finally, one significant restriction of the proposed framework is that it is applicable for a limited number of alternatives (e.g. limited number of destinations), where extreme difficulty would be added to the estimation process as the number of alternatives increases. However, it may represent a more effective and accurate alternative of the first three stages in traditional fourstep model while analysing the discretionary trips for small or medium sized cities with only a limited number of discretionary destinations.
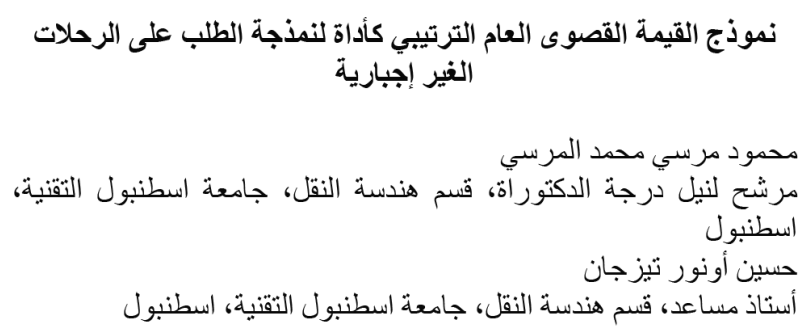

الخلاصة

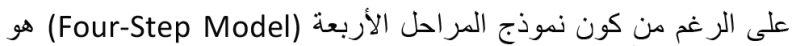

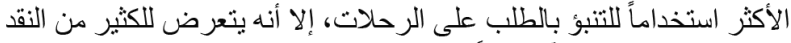

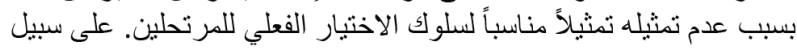

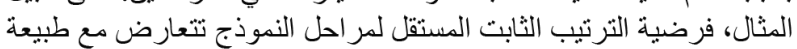

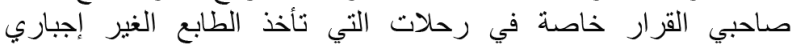

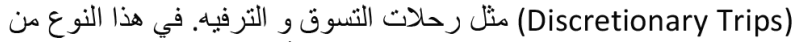

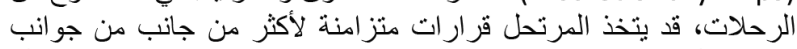

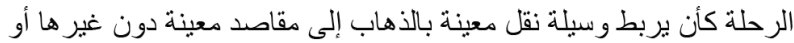

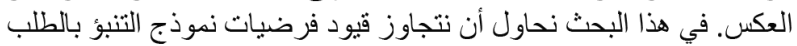

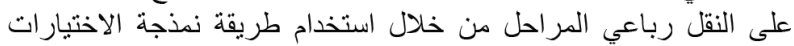

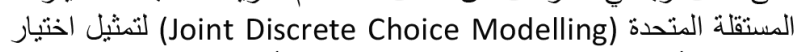

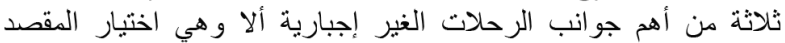
و (Destination)

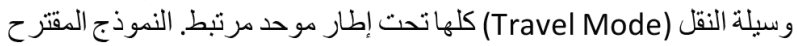
للاستخدام هو نموذج القيمة القصوى العام الترتيبي (Geded) (Generalized Extreme Value Model

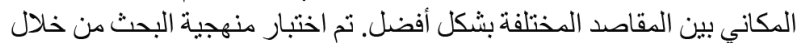

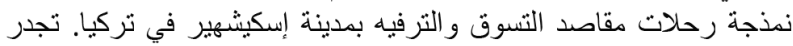

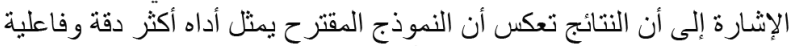

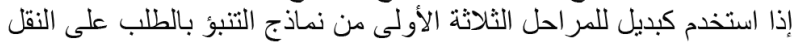

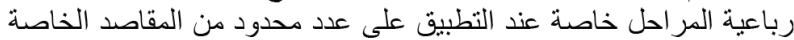
بالرحلات الغير إجبارية

كلمات مفتاحية: نموذج القيمة القصوى العام الثرتيبي، المقصد، وقت بداية

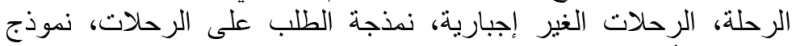

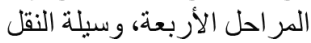

\section{REFERENCES}

[1] Ortuzar JD, Willumsen LG. Modelling Transport. New York: John Wiley \& Sons, Inc.; 2011. p. 23.

[2] Marshall N. Pre-destination-choice walk mode choice models. In: Proceedings of the $97^{\text {th }}$ Meeting of the Transportation Research Board Annual Meeting, Washington DC; 2018.

[3] Hassan MN, Najmi A, Rashidi TH. Recreational destination choice modelling incorporating fuzzy logic in discrete choice modeling. In: Proceedings of the $96^{\text {th }}$ Meeting of the Transportation Research Board Annual Meeting, Washington DC; 2017.

[4] Molloy J. Development of a destination choice model for Ontario. MSc thesis. Technical University of Munich; 2016. 
[5] Yoon S, Deutsch K, Chen Y, Goulias K. Feasibility of using time-space prism to represent available opportunities and choice sets for destination choice models in the context of dynamic urban environments. Transportation. 2012;39: 807-823.

[6] Scott DM, He SY. Modeling constrained destination choice for shopping: A GIS-based, time geographic approach. Journal of Transport Geography. 2012;23: 60-71.

[7] Auld JA, Mohammadian A. Planning constrained destination choice in the adapts activity-based model. In: Proceedings of the $91^{\text {st }}$ annual conference of the Transportation Research Board, Washington DC; 2011.

[8] Bhat C, Govindarajan A, Pulugurta V. Disaggregate attraction-end choice modeling. Transportation Research Record: Journal of the Transportation Research Board. 1998;1645: 60-68.

[9] Miller E, Kelly MO. Estimating shopping destination choice models from travel diary data. Professional Geographer. 1983;35(4): 440-449.

[10] Pozsgay MA, Bhat CR. Destination Choice Modeling for Home-Based Recreational Trips: Analysis and Implications for Land Use, Transportation, and Air Quality Planning. Journal of Transportation Research Record. 2001;1777: 47-54

[11] Rasouli S, Timmermans H. Activity-based models of travel demand: Promises, progress and prospects. International Journal of Urban Sciences. 2013;18(1): 31-60.

[12] Ben-Akiva M. Passenger travel demand forecasting: Applications of disaggregate models and directions for research. In: Visser EJ. (eds) Transport Decisions in an Age of Uncertainty. Dordrecht: Springer; 1977. p. 183-93.

[13] Daly A. Estimating choice models containing attraction variables. Transportation Research Part B: Methodological. 1982;16: 5-15.

[14] Simma A, Schlich R, Axhausen KW. Destination choice modelling for different leisure activities. Institut für Verkehrsplanung und Transporttechnik, Strassen- und Eisenbahnbau, ETH Zürich, 2002.

[15] Mishra S, Wang Y, Zhu X, Moeckel R, Mahaparta S. Comparison between gravity and destination choice models for trip distribution in Maryland. Transportation Research Board 92 ${ }^{\text {nd }}$ Annual Meeting, 13-17 Jan 2013, Washington DC, US.

[16] Hassan MN. Najmi A, Rashidi TH. Recreational destination choice modelling incorporating Fuzzy Logic in discrete choice modelling. In: Proceedings of the 96th Meeting of the Transportation Research Board Annual Meeting, Washington, DC; 2017.

[17] Bhat CR. An analysis of travel mode and departure time choice for urban shopping trips. Transportation Research B. 1998;32(6): 361-371.
[18] Bates J, Polak J, Jones P, Cook A. The valuation of reliability for personal travel. Transportation Research E. 2001;37: 191-229.

[19] Elmorssy M, Tezcan HO. Examining potential correlation among departure time, destination and transportation mode for discretionary trips: A case study of shopping and entertainment trips. In: Proceedings of the $98^{\text {th }}$ Transportation Research Board Annual Meeting. Washington, DC; 2019.

[20] Bhat CR. A Multiple Discrete-Continuous Extreme Value model: formulation and application to discretionary timeuse decisions. Transportation Research B. 2005;39(8): 679-707.

[21] Bhat CR. The Multiple Discrete-Continuous Extreme Value (MDCEV) model: Role of utility function parameters, identification considerations, and model extensions. Transportation Research B. 2008;42(3): 274-303.

[22] Pinjari AR, Bhat CR. A Multiple Discrete-Continuous Nested Extreme Value (MDCNEV) model: Formulation and application to discretionary activity time-use and timing behavior on weekdays. Transportation Research B. 2010;44(4): 562-583.

[23] Yagi S, Mohammadian A. An Activity-Based Microsimulation Model of travel demand in the Jakarta metropolitan area. Journal of Choice Modelling. 2010;3(1): 32-57.

[24] Shiftan Y. Practical approach to model trip chaining. Journal of the Transportation Research Board. 1998;1645: 17-23.

[25] Outwater ML, Bradley M, Ferdous N, Bhat C, Pendyala R, Hess S, LaMondia J. Tour-based national model system to forecast long-distance passenger travel in the United States. In: Proceedings of the $94^{\text {th }}$ Transportation Research Board Annual Meeting; 2015. No. 15-4322.

[26] Bowman JL, Ben-Akiva M. Activity-based disaggregate travel demand model system with activity schedules. Transportation Research A. 2001;2(1): 1-28.

[27] Newman JP, Bernardin VL. Hierarchical ordering of nests in a joint mode and destination choice model. Transportation. 2010;37(4): 677-88.

[28] Mishra S, Ye X, Ducca F, Knaap G-J. A functional integrated land use-transportation model for analyzing transportation impacts in the Maryland-Washington, DC Region. Sustainability: Science, Practice and Policy. 2011;7(2): 60-9.

[29] Small KA. A discrete choice model for ordered alternatives. Econometrica. 1987;55(2): 409.

[30] Bhat CR. Accommodating flexible substitution patterns in multi-dimensional choice modeling: Formulation and application to travel mode and departure time choice. Transportation Research Part B: Methodological. 1998;32(7): 455-66. 